\title{
ЭКОЛОГИЧЕСКАЯ ПОЗИЦИЯ КАК ИСТОЧНИК СУБЪЕКТИВНЫХ УБЕЖДЕНИЙ ОБ ЭФФЕКТИВНОСТИ ДЕЙСТВИЯ
}

\author{
Баева Карина \\ Харьковский национальный университет имени В. Н. Каразина, \\ Харьков, Украина, \\ baieva.karina@gmail.com \\ https://orcid.org/0000-0002-4840-3808
}

Цель. Ныне человечество живет в мире, где сложно не заметить негативные экологические изменения. Деятельность каждого является основной причиной трансформаций в природной среде. Для того, чтобы остановить деградацию в природе, всем представителем человеческого вида нужно объединиться и совершать больше «экологически дружелюбных», нежели разрушающих поступков, но такая смена направленности поведения зависит от многих факторов. В этой работе мы сконцентрировались на личностных факторах экологического поведения индивида. Цель нашей статьи - рассмотрение экологической позиции в качестве основы самоэффективности субъекта и последующее изучение возможных влияний на эмпирических данных. В рамках теоретического анализа обсуждаются этапы развития экологической самоэффективности в зависимости от доминирующих биосферных или финансово-экономических смыслов в экологической позиции. Предполагается, что экологическая самоэффективность воздействует на общую самоэффективность личности.

Memoды. Предположение проверялось при помощи корреляционного (коэффициент ранговой корреляции Спирмена) и регрессионного (множественная регрессия) анализа, а также моделирования структурными уравнениями.

Результаты. В результате статистического анализа выявлено, что экологическая позиция влияет на общую самоэффективность, опосредовано через экологическую самоэффективность.

Bыводы. Установлено, что в зависимости от ценности как ресурса жизнеобеспечения - денег или биосферы - снижается или повышается вера человека в продуктивность личных поступков в области выполнения различных повседневных задач, опосредовано через уверенность человека в возможности собственными и общечеловеческими действиями улучшить экологическую ситуацию на планете.

Ключевые слова: жизненная позиция личности, личностные смыслы и представления, мировоззренческие взгляды, самоэффективность, внутренняя мотивация и ресурсы, развитие экологической самоэффективности, субъект.

ISSN 2308-3743 (Online), ISSN 2227-1376 (Print)

(C) Баева К., 2020. Ця стаття відкритого доступу на умовах CC BY-NC 4.0 


\section{Bayeva Karina. Ecological Position as a Source of Subjective Beliefs} Regarding the Efficiency of Action. Purpose. Currently, humanity lives in a world where it is hard not to notice the negative environmental changes. Everyone's activity is the primary cause of transformations in the natural environment. To stop the degradation in nature, all representatives of human species need to unite and perform more «ecologically friendly», rather than destructive actions, but such direction change in behaviour depends on many factors. In this paper, the focus is made on the personality determinants of an individual's ecological behaviour. The presented article aims to consider the ecological position as the basis for self-efficacy of a subject and subsequent study of possible effects on empirical data. The development stages of ecological self-efficacy are discussed in terms of theoretical analysis depending on the dominant biosphere or financial and economic senses in the ecological position. It has been suggested that ecological self-efficacy of a personality affects the general one.

Methods. As a result of empirical analysis, it has been determined that ecological position indirectly affects the general one through the ecological self-efficacy. The assumption has been verified using correlation (Spearman's rank correlation coefficient) and regression (multiple regression) analysis, as well as modelling by structural equations.

Results. As a result of statistical analysis, it has been revealed that ecological position indirectly affects the general one through the ecological self-efficiency.

Conclusions. It has been determined that depending on the value as life support resource - money or biosphere, people's faith in the productivity decreases or increases in their actions in the field of performing various daily tasks, indirectly through the human confidence in the possibility to improve the ecological situation on the planet by their own and common human actions.

Key words: personality life position, personality senses and ideas, worldviews, self-efficacy, internal motivation and resources, ecological self-efficacy development, subject.

Басва Каріна. Екологічна позиція як джерело суб'сктних переконань щодо ефективності дії. Мета. Нині людство живе у світі, де складно не помітити негативні екологічні зміни. Діяльність кожного $є$ основною причиною трансформацій у природному оточенні. Для того, щоб зупинити деградацію в природі, усім представникам людського виду потрібно об'єднатися й робити більше «екологічно доброзичливих», ніж екологічно руйнівних вчинків, але така зміна спрямованості поведінки залежить від багатьох факторів. У цій роботі ми зосередилися на особистісних чинниках екологічної поведінки індивіда. Метою нашої статті став розгляд екологічної позиції як основи самоефективності суб'єкта та наступне вивчення можливих впливів на емпіричних даних. У рамках теоретичного аналізу розглянуто етапи розвитку екологічної самоефективності залежно від домінуючих біосферних або фінансово-економічних сенсів в екологічній позиції. Висунуто припущення, що екологічна самоефективність впливає на загальну самоефективність особистості. 
Методи. У результаті емпіричного аналізу виявлено, що екологічна позиція впливає на загальну самоефективність опосередковано через екологічну самоефективність. Припущення перевірено за допомогою кореляційного (коефіцієнт рангової кореляції Спірмена) та регресійного (множинна регресія) аналізу, а також моделювання структурними рівняннями.

Результати. У результаті статистичного аналізу виявлено, що екологічна позиція впливає на загальну самоефективність опосередковано через екологічну самоефективність.

Висновки. Установлено, що залежно від цінності як ресурсу життєвабезпечення - грошей або біосфери - знижується або підвищується віра особи в продуктивність іiї вчинків у сфері виконання різних повсякденних завдань, опосередковано через упевненість людини в можливість власними й загальнолюдськими діями поліпшити екологічну ситуацію на планеті.

Ключові слова: життєва позиція особистості, особистісні сенси та уявлення, світоглядні погляди, самоефективність, внутрішня мотивація та ресурси, розвиток екологічної самоефективності, суб'єкт.

Постановка проблемы. Деградация природной среды антропогенная и глобальная, но информация о росте экологических проблем интерпретируется различно. Позитивные или негативные трансформации в мир природы приносит поведение человека. Сейчас важно упростить переход от вредящего взаимодействия к улучшающему состояние экосистем. Сохраняющая или разрушающая направленность поведенческих актов в большей мере определяется убеждениями об эффективности проэкологических действий. Уровень экологической самоэффективности зависит от субъективной трактовки угрозы природному балансу и благосостоянию человечества. Поэтому важно изучение факторов, которые влияют на оценку экологической ситуации и личной эффективности.

Анализ последних исследований и публикаций. Согласно А. Бандуре, самоэффективность как убеждение человека в успехе его действий в какой-либо сфере или ситуации способно запускать настойчивость в решение сложных задач (Бандура, 2000). Самоэффективность являться мировоззренческим конструктом, внутренним мерилом, которое измеряет продуктивность поступков (Даценко, 2020). В обеих случаях самоэффективность становиться средством стимулирования каких-то социально значимых действий. Особенность самоэффективности заключается в том, что она субъективна и имеет четыре источника. К факторам развития высокой самоэффективности входят личный опыт эффективного действия; пример эффективности 
других людей в сложной или схожей ситуации; поощрение или критика со стороны окружающих; физическое и эмоциональное состояние. Необходимо добавить, что поощрение или критика со стороны самые слабые из перечисленных источников личной убежденности в эффективности индивида, собственные успешные действия - наиболее сильный (Бандура, 2000; Булынко, Коломейцев, 2009; Bandura, 1996). Для нас значимы две теоритические характеристики воспринятой производительности действий. Мы рассмотрим их относительно экологической самоэффективности. Первый момент позволяет утверждать, что экологическая самоэффективность стимулирует настойчивость и позволяет не мирится с экологическими проблемами; второй служить порукой обсуждения необходимых предпосылок развития экологической самоэффективности.

Для роста экоэффективности действующему субъекту нужны:

1) опыт или знания об успехах окружающих в уменьшении экологических угроз;

2) обратная связь о правильных проэкологических (сберегающих) действиях;

3) умение противодействовать физическому и эмоциональному истощению.

Точнее говоря, навык при наблюдении несправедливого отношения к другим животным или получении сообщений об усугублении состояния природной среды сохранять желание менять нынешние реалии (Бандура, 2000; Булынко, Коломейцев, 2009; Кряж, 2012; Bandura, 1996; Chen, 2015; Pajares, 1997; Zimmerman, 2000).

Идеи А. Бандуры об источниках самоэффективности свидетельствуют в пользу того, что она подчинена когнитивной (человек обрабатывает обратную связь и информацию об опыте других), эмоциональной (настроение человека может повысится или понизится его эффективность) и поведенческой (человек повышает свою эффективность через практику) сферам психики человека. Именно по этой причине мы ожидаем, что на экологическую самоэффективность воздействует экологическая позиция субъекта (Кряж, 2012; Bandura, 1996; Pajares, 1997).

Восприятие и способы реагирования на глобальные экологические угрозы во многом обусловлены экологической позицией воспринимающего субъекта, т.е. зависят от жизненной позиции субъекта, заданной соотношением биосферных и финансово-экономических («денеж- 
ных») смыслов при восприятии экологической действительности (Кряж, 2012). Названная мировоззренческая позиция в зависимости от доминирующего смысла определяет приоритетный ресурс жизнедеятельности в представлениях личности (биосфера или деньги) и направленность ее экологического поведения. Другими словами, человек субъективно наделяет первенствующим значением в своем жизнеобеспечении биосферу или деньги, следовательно - различно оценивает экологические реалии. Мы сконцентрируемся на трех различиях в оценке экологической действительности субъектом экологической позиции.

Во-первых, человек склонен замечать или нет экологические проблемы, экоактивистов, т.е. видеть или игнорировать повод и примеры других для сдвигов своей экологической эффективности. Вовторых, человек более заинтересован в сохранении биосферы или денег, отчего по-разному эмоционально откликается на вред природе. В-третьих, человек больше готов к различным линиям поведения, которые формирует больше опыт сбережения или разрушения (Кряж, 2012; Bandura, 1996; Pajares, 1997). Стало быть, можно ожидать, что субъекты с доминированием биосферных смыслов в экологической позиции склонны искать информацию о том, как улучшить состояние окружающей среды, чтобы сохранить свой ресурс жизнедеятельности - биосферу (там же). Поиск информации открывает дорогу к получению сведений о сберегающих действиях в природной среде и других людей, которые эффективно вносят в сохранение жизни на планете. Знание того, как действовать, чтобы улучшить состояние окружающей среды, и позитивный пример других должны повысить самоэффективность человека в сфере решения экологических проблем (Булынко, Коломейцев, 2009; Кряж, 2015; 2012; Bandura, 1996). Это частично согласуется с исследованием К. Табернеро, Б. Эрнандес, где внутренняя мотивация и самоэффективность выступили условиями проэкологического поведения (Tabernero, Hernández, 2011). Также В. Абрахамс и Л. Стег обнаружили, что потребители ведут себя более энергосберегающе, если они понимают, что негативно влияют на окружающую среду (Lee, 2016). Вместе с тем, мы предполагаем, что главная причина низкой экологической самоэффективности при доминировании денежных смыслов в экологической позиции состоит в том, что биосфера не обладает внутренней ценностью для человека. У него нет внутренних мотивов задействовать имманентные ресурсы 
для преодоления экологических проблем (Бандура, 2000; Булынко, Коломейцев, 2009). В силу того, что самоэффективность может изменяться в течение времени, мы не утверждаем, что субъекты с доминированием денежных смыслов в экологической позиции не смогут развить высокий уровень экологической самоэффективности, просто им нужно преодолеть ряд психологических преград (Pajares, 1997; Zimmerman, 2000). Для субъектов с доминированием денежных смыслов в экологической позиции экологическая информация превратиться в актуальную и толчок для роста экологической самоэффективности, когда проблемы в природной среде потенциально угрожают близкому человеку (Бандура, 2000; Булынко, Коломейцев, 2009). Поэтому далее представлено описание трех условных этапов развития экологической самоэффективности.

Первыц этап: субъекты с доминированием биосферных смыслов в экологической позиции в момент восприятия информации об экологических проблемах переживают надежду на решение этих проблем, в это время как субъекты с доминированием денежных смыслов безысходность и безразличие. Основой надежды будет желание сохранить единство с экологическим сообществом. Очевидным базисом безысходности будут сведения о значимости для человека «здоровой» природной среды, безразличие включается из-за небезопасности мира с экологическими проблемами (Бандура, 2000; Булынко, Коломейцев, 2009; Кряж, 2015; 2012; Bandura, 1996; Chen, 2015; Lee, 2016; Ojala, 2012; Tabernero, Hernández, 2011). Скрытой основой как безысходности, так и безразличия является воспринятая сила денег в жизни вместе с бессознательным пониманием, что деньги бесполезны в оживлении экосистем планеты, не укроют от «вихря» экологических проблем. Главным резервом высокой или низкой самоэффективности на этом этапе выступает восприимчивость-бесчувственность к вреду природе.

Bторой этап: субъекты с доминированием биосферных смыслов в экологической позиции, вероятно, будут испытывать веру в собственные действия - индивидуальную самоэффективность. Развитие этой индивидуальной уверенности связано с приростом экологической осведомленности и проэкологическим примером других. Субъекты с доминированием денежных смыслов в экологической позиции испытывают веру в деньги и другие изобретения, из-за чего имеют низкую осведомленность. 
Уровень осведомленности напрямую обусловлен уже упомянутыми различиями в представлениях субъектов относительно главного ресурса для жизнедеятельности. Здесь осведомлённость представляется рычагом изменения самоэффективности (Gupta, Singh, 2019; Lee, 2016; Ojala, 2012; Pajares, 1997; Tabernero, Hernández, 2011).

Tретий этап: субъекты с доминированием биосферных смыслов в экологической позиции обретают высокую экологическую самоэффективность, во-первых, через воплощение индивидуальной самоэффективности на практике; во-вторых, через укрепление уверенности в успехе собственных сберегающих действий, наблюдение за эффективными примерами окружающих. На данном этапе ресурс высокой или низкой самоэффективности находится в наличии или отсутствии практического опыта проэкологических действий.

Субъекты с доминированием денежных смыслов в экологической позиции не имеют внутренних мотивов для проэкологических действий, если это не приносит денег, тем самым, упускают возможности повысить эффективности в экологической сфере путем как собственных проэкологических действий, так и опыта других. Однако не стоит забывать способность самоэффективности в одной сфере переноситься на другую сферу деятельности, если учесть это у субъектов с доминированием биосферных смыслов в экологической позиции самоэффективность в области решения экологических проблем, предположительно, станет фундаментом общей самоэффективности (если та слабо выражена). Экологическая самоэффективность охватывает веру человека в эффективность действий в области, которая намного глобальней повседневных социальных задач и деятельности (Бандура, 2000; Tabernero, Hernández, 2011). Человек, который верит, что собственными действиями может влиять на состояние окружающей среды на мировом уровне, скорее верит в то, что способен изменить свою жизнь, эффективно отвечать на социальные задачи и профессиональные вызовы (Chen, 2015; Gupta, Singh, 2019; Lee, 2016; Ojala, 2012; Hernández, 2011; Tabernero, Zimmerman, 2000). Вместе с тем, общая самоэффективность субъектов с доминированием денежных смыслов в экологической позиции, вероятно, станет основой экологической самоэффективности (если та слабо выражена) (там же). Общая самоэффективность в нужный момент будет питать настойчивость в поиске экологической информации и сформирует веру в 
успешное решение экологических проблем (Бандура, 2000; Bandura, 1996; Chen, 2015; Ojala, 2012).

Цель нашего исследования - изучение влияния экологической позиции на самоэффективность. Цель можно представить в двух эмпиричных задачах: 1) изучить взаимосвязи между экологической позицией и самоэффективностью в различных сферах; 2) исследовать специфику влияния экологической позиции на субъективные убеждения в самоэффективность.

Выборка и методы исследования. Для изучения экологической позиции использовался опросник экологических установок «ЭкО 30» (И. В. Кряж), направленный на исследование установок по отношению к проблеме глобальных экологических изменений (30 утверждений). В данной работе использовались такие показатели, как биоцентризм ( $a$ Кронбаха=0,64); «Деньги» (финансово-экономические приоритеты) ( $a$ Кронбаха=0,65).

Изучение самоэффективности производили при помощи шкалы общей самоэффективности Р. Шварца, М. Ерусалема (Ромек, 1996) и опросника экологической самоэффективности в контексте климатических изменений M. Ojala (Ojala, 2012) (в адаптации и модификации И. В. Кряж). Модификация заключалась в замене словосочетания «климатические изменения» в пунктах на «экологические изменения». Данные инструменты позволили получить такие показатели, как экологическая самоэффективность ( $a$ Кронбаха=0,75); общая самоэффективность ( $a$ Кронбаха=0,85).

В исследовании приняли участие 194 человека (126 женщин и 68 мужчин): 74 студента факультета психологии ХНУ им. В. Н. Каразина (средний возраст - 24,1 лет) и 120 случайно отобранных респондентов (средний возраст - 28,4 лет). Анализ данных проводился при помощи ранговой корреляции Спирмена, регрессионного анализа; моделирования структурными уравнениями (метод ADFG).

Результаты и их обсуждения. В результате корреляционного анализа установлены взаимосвязи между переменными-показателями экологической позиции: биоцентризм и «Деньги» с экологической самоэффективностью $(0,39, \mathrm{p}<0,01 ;-0,52, \mathrm{p}<0,01)$. Данная связь созвучна, к примеру, с работой Х. Хуанга, где наблюдается положительная корреляция экологических представлений и экологической самоэффективности (Huang,2016). Также установлена корреляция между экологической и общей самоэффективностью $(0,26, \mathrm{p}<0,01)$ 
(см. табл. 1). Взаимосвязи демонстрируют, что показатели экологической позиции не связаны линейной связью с уверенностью человека в своей повседневной продуктивности, но связь общей самоэффективности с экологической эффективностью свидетельствует о возможном опосредованном влиянии.

Таблица 1

Значимые корреляции между показателями экологической позиции и самоэффективностью

\begin{tabular}{|c|c|c|}
\hline Переменные & Биоцентризм & $\begin{array}{c}\text { Экологическая } \\
\text { самоэффективность }\end{array}$ \\
\hline Деньги &,$- 55 * *$ &,$- 52 * *$ \\
\hline $\begin{array}{c}\text { Экологическая } \\
\text { самоэффективность }\end{array}$ &, $39 * *$ & - \\
\hline $\begin{array}{c}\text { Общая } \\
\text { самоэффективность }\end{array}$ & - &, $26 * *$ \\
\hline
\end{tabular}

Примечание к табл. 1. Метод ранговых коррелящий Спирмена, значимость $*=p<0,05 ; * *=p<0,01$.

Выявленные взаимосвязи демонстрируют необходимость изучения сначала влияния биоцентризма, денег на экологическую самоэффективность. Затем происходило исследование влияния самоэффективности в экологической сфере на оценку особой полезности личных действий в решении жизненных задач с применением регрессионного анализа (см. табл. 2).

Таблица 2

\section{Результаты регрессионного анализа (значимость на уровне **p $<0,001$ и *p<0,01)}

\begin{tabular}{|c|c|c|}
\hline \multirow[t]{2}{*}{ Предикатор } & \multicolumn{2}{|c|}{ Зависимые переменные } \\
\hline & $\begin{array}{c}\text { экологическая } \\
\text { самоэффективность }\end{array}$ & $\begin{array}{c}\text { общая } \\
\text { самоэффективность }\end{array}$ \\
\hline Биоцентризм & beta $=, 34 ; \mathrm{F}=25,20 ; \mathrm{R}_{\text {скор. }=11 * *}$ & - \\
\hline Деньги & beta $=-45 ; \mathrm{F}=49,41 ; \mathrm{R}_{\text {скор. }=20 * *}^{2}$ & - \\
\hline $\begin{array}{c}\text { Экологическая } \\
\text { самоэффективность }\end{array}$ & - & $\begin{array}{l}\text { beta }=, 27 ; \\
\mathrm{F}=16,27 ; \mathrm{R}_{\text {скор. }}^{2} 07^{*}\end{array}$ \\
\hline
\end{tabular}

Выявлено, что «Биоцентризм» и «Деньги» в качестве независимых переменных объясняют $11 \%$ и 20 \% общей дисперсии переменной «Экологическая самоэффективность». Выходит, что беспокойство о биосфере укрепляет уверенность человека, что он способен повлиять 
позитивно на состояние природной среды, в то время как вера во всесильность денег снижает такую уверенность. Вместе с этим, экологическая самоэффективность как предиктор объясняет 7 \% общей дисперсии показателя общей самоэффективности. Получается, что ожидание успеха действий в экологической сфере вправду может оказывать слабое, но позитивное влияние на убеждённость в эффективности действий относительно привычных будничных задач человека.

Корреляционный и регрессионный анализ подтверждают правомерность дальнейшего изучения направленностей прямого и косвенного влияния экологической позиции на самоэффективность личности. По этой причине нами построена и проверена структурная модель (рис. 1).

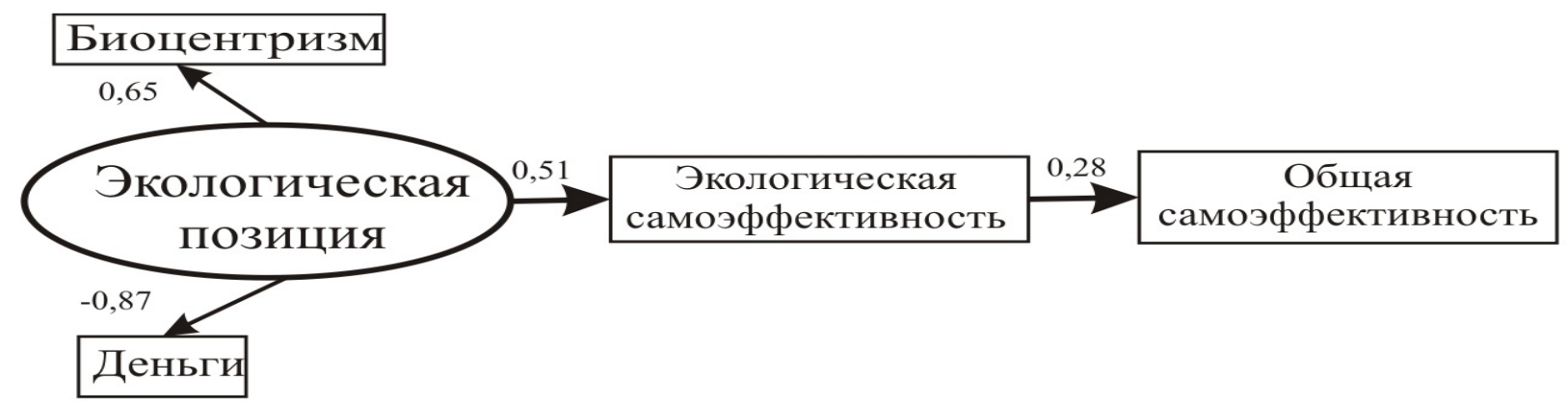

Рис. 1. Модель влияния экологической позиции на самоэффективность Примечание. Все коэффициенты путей значимы на уровне $p<0,001$.

Модель представлена латентным фактором «Экологическая позиция» (манифестует в себя экологические установки: биоцентризм и «Деньги», (финансово-экономические приоритеты)); манифестными переменными «Экологическая самоэффективность» и «Общая самоэффективность». Показатели пригодности: $\chi 2 / \mathrm{df}=1,79 / 2 ; \mathrm{p}=0,41$; RMSEA 0,035; GFI 0,99; AGFI 0,97. Соответственно, экологическая позиция субъекта влияет на общую самоэффективность, опосредованно через самоэффективность в экологической сфере. Возможно, взгляд на биосферу как приоритетный ресурс в обеспечении жизнедеятельности, способствует виденью в себе способности улучшить состояние среды. В конечном итоге, «примерка» роли эффективного субъекта экологических перемен приводит к надстройке на благополучное решение обыденных задач. 
Результаты свидетельствуют в пользу того, что беспокойство о состоянии биосферы положительно сказывается на вере человека в то, что он по средствам экологически ответственных действий способен внести свой вклад в улучшение экилогической обстановки. Установленный эмпирический факт совпадает с исследованиями, показавшими, что люди, обеспокоенные состоянием среды, склоны испытывать личную эффективность. Например, согласно работе П. Стерна сообщения, релевантные экологическому мировоззрению адресата, воспринимались как более эффективные (Ramkissoon, Smith, 2014). Х. Рамкиссун и Л. Смит установили, что экологическое мировоззрение влияет на личную эффективность, хотя и опосредовано, через эмоции (там же). В нашем исследовании показано, что вера в эффективность действий в экологической сфере связана с верой в эффективность действий относительно более обыденных задач, что согласуется, например, с более ранними исследованиями, где самоэффективность в решениях одних математических задач переноситься на убеждённость в возможность решить другие похожие математические задачи (Pajares, 1997).

Главное, что, описанная модель подтвердила наше предположение, что экологическая позиция способна воздействовать на субъективные убеждения человека относительно продуктивности его действий в преодолении любых трудностей повседневной жизни, опосредовано через воздействие на ожидание высокой результативности проэкологических действий в области экосохранения. Представления в экологической позиции человека (ценность экосистем, общность с экологическим сообществом и др. или жажда материального благополучия, связи с социально-экономической системой и др.) способны подавить или спровоцировать человека проявлять себя как сознательного субъекта в разных аспектах. Сначала стать фигурой, верящей в действенность своих поступков для остановки негативных экологических метаморфоз, затем - фигурой, убеждённой в высокой продуктивности действия при встрече с обыденными задачами (Кряж, 2012; Родина, 2013).

Выводы и перспективы дальнейших исследований. Экологическая позиция связана прямо с экологической самоэффективностью, но не коррелирует с общей самоэффективностью. Также установлено, что экологическая позиция воздействует на общую самоэффективность, опосредовано через экологическую самоэффективность, т.е. веру в возможность своими усилиями достичь трудноосуществимых целей в 
повседневной жизни, опосредованно - через убежденность в продуктивности действий, общечеловеческих интервенций для решения экологических проблем. На основе этих результатов подтверждается, что субъективные убеждения человека в эффективности в жизни находиться под влиянием соображений о главном ресурсе, который удовлетворяет его житейские потребности: в биосфере или деньгах, и оценке личной возможности действиями улучшить состояние природной среды. Соотношение биосферных или денежных смыслов в экологической позиции выступают внутренними силами, которые активизируют желание стать эффективным, заметный вклад в значимые сферы. Главным основанием данного стремления будет более вероятное глобальное осмысление тяжелых экологических ситуаций у субъектов с доминированием биосферных смыслов в экологической позиции, позволяющее воспринять такое событие не как отдельное, а осмыслить, как ценностное относительно всей жизни и места в мире. Субъектам с доминированием денежных смыслов в экологической позиции, вероятно, присуще ситуативное осмысление экологических угроз, они посмотрят на критические события отдельно, если найдут в них значимые элементы, станут решать (повышать эффективность), если нет - избегать (снижать эффективность).

Приведенные результаты имеют ряд ограничений. Выборка по фактору пола является неравномерной. Часть выборки составили студенты, изучающие курс «Экологическая психология», направленный, в том числе, на формирование у них экологического мировоззрения. Также у респондентов не оценивались уровни экологической осведомленности, развития конкретных проэкологических навыков. В перспективе необходимы исследования, во-первых, на других, более многочисленных выборках с контролем числа респондентов по фактору пола, воздействий специфических условий деятельности участников; во-вторых, с учетом уровней развития конкретных проэкологических навыков и экологической осведомленности.

\section{Литература}

1. Бандура, А. (2000). Теория соичального научения. Санкт-Петербург: Евразия.

2. Булынко, Н. А. Коломейцев, Ю. А. (2009). К проблеме самоэффективности личности в психологии. Веснік Мазырскага дзяржаўнага педагагічнага ўніверсітэта імя I. П. Шамякіна, № 3(24), 38-44. 
3. Даценко, О. А. (2020). Теоретичні засади дослідження проблеми самоефективності як психологічного феномена. Вісник університету імені Альфреда Нобеля. Серія: Педагогіка і психологія. Педагогічні науки, № 1 (19), 35-41.

4. Кряж, И. В. (2015). Влияние экологической позиции личности на отношение к экологической кинопродукции. Universum: Психология и образование: электрон. науч. журн., № 8(18), URL: http://7universum.com/ru/psy/archive/ item/2511.

5. Кряж, И. В. (2012). Психология глобальных экологических изменений: монография. Харьков: ХНУ им. В. Н. Каразина.

6. Родіна, Н. В. (2013). Психологія копінг-поведінки: системне моделювання: дис. ... д-ра психол. наук; Київський нац. ун-т ім. Т. Г. Шевченка, 506 с.

7. Ромек, В. Г. (1996). Русская версия шкалы общей само-эффективности Р. Шварцера и М. Ерусалема. Иностранная психология, 1996, 7, 71-77.

8. Bandura, A. (1994). Self-efficacy. In V. S. Ramachaudran (Ed.), Encyclopedia of human behavior. New York: Academic Press. (Reprinted in H. Friedman [Ed.], Encyclopedia of mental health). San Diego: Academic Press, 4, 71-81.

9. Chen, M. F. (2015). Self-efficacy or collective efficacy within the cognitive theory of stress model: Which more effectively explains people's self-reported proenvironmental behavior? Journal of Environmental Psychology, 42, 66-75. DOI: https://doi.org/10.1016/j.jenvp.2015.02.002

10. Gupta, A., \& Singh, U. (2019). Factors Affecting Environmentally Responsive Consumption Behavior in India: An Empirical Study. Jindal Journal of Business Research, 8(1), 16-35. DOI: https://doi.org/10.1177/2278682118810274

11. Huang, H. (2016). Media use, environmental beliefs, self-efficacy, and proenvironmental behavior. Journal of Business Research, 69(6), 2206-2212. DOI: https://doi.org/10.1016/j.jbusres.2015.12.031

12. Lee, J. W. (2016). Energy conservation behavioral intention: attitudes, subjective norm and self-efficacy. International Conference on New Energy and Future Energy System, 1088/1755. DOI: https://doi.org/10.1088/1755-1315/40/ $1 / 012087$

13. Ojala, M. (2012). How do children cope with global climate change? Coping strategies, engagement, and well-being. Journal of Environmental Psychology, 32(3), 225-233. DOI: https://doi.org/10.1016/j.jenvp.2012.02.004

14. Pajares, F. (1997). Current Directions in Self-Efficacy Research. In M. Maehr, \& P. R. Pintrich (Eds.), Advances in Motivation and Achievement, 10, 1-49.

15. Ramkissoon, H. R., \& Smith, L. D. G. (2014). The relationship between environmental worldviews, emotions and personal efficacy in climate change. International Journal of Arts \& Sciences, 7(1), 93.

16. Tabernero, C., \& Hernández, B. (2011). Self-efficacy and intrinsic motivation guiding environmental behavior. Environment and Behavior, 43(5), 658-675.

17. Zimmerman, B. J. (2000). Self-efficacy: An essential motive to learn. Contemporary educational psychology, 25(1), 82-91. 


\section{References}

1. Bandura, A (2000). Teorija social'nogo nauchenija [Social learning theory]. Sankt-Peterburg: Evrazija (in Russian).

2. Bulynko, N. A. Kolomejcev, Ju. A. (2009). K probleme samojeffektivnosti lichnosti v psihologii [«To the problem of self-efficacy personality in psychology»]. Vesnik Mazyrskaga dzjarzhay̆naga pedagagichnaga y̆niversitjeta imja I. P. Shamjakina, 3(24), 38-44 (in Russian).

3. Dacenko, O. A. (2020). Teoretyčni zasady doslidžennja problemy samoefektyvnosti jak psyxolohičnoho fenomena [Theoretical fundamentals of the problem research self-efficiency as a psychological phenomenon]. Visnyk universytetu imeni al'freda nobelja. serija «Pedahohika i psyxolohija». Pedahohični nauky, 1 (19), 35-41 (in Ukrainian).

4. Kryazh, I. V. (2015). Vlija jekologichesknieoj pozicii lichnosti na otnoshenie $\mathrm{k}$ jekologicheskoj kinoprodukcii [Influence of person's ecological position on the attitude to ecological motion pictures]. Universum: Psihologija $i$ obrazovanie: jelektron. nauch. zhurn., 8(18), available at: http://7universum.com/ru/psy/archive/ item/2511 (in Russian).

5. Kryazh, I. V. (2012). Psihologija global'nyh jekologicheskih izmenenij: monografija [The psychology of global environmental change]. Harkov: HNU im. V. N. Karazina (in Russian).

6. Rodina, N. V. (2013). Psyhologija koping-povedinky: systemne modeljuvannja: dys. ... d-ra psyhol. nauk [Psychology of copying behavior: systemic modeling: dis. ... Dr. psychol. of sciences]. Kyiv, 504 (in Ukrainian).

7. Romek, V. G. (1996). Russkaja versija shkaly obshhej samo-jeffektivnosti R. Shvarcera i M. Erusalema [Russian version of the scale of general self-efficiency of R. Shvartser and M. Erusalem]. Inostrannaja psihologija, 7, 71-77 (in Russian).

8. Bandura, A. (1994). Self-efficacy. In V. S. Ramachaudran (Ed.), Encyclopedia of human behavior. New York: Academic Press. (Reprinted in H. Friedman [Ed.], Encyclopedia of mental health) San Diego: Academic Press, 4, 71-81 (in English).

9. Chen, M. F. (2015). Self-efficacy or collective efficacy within the cognitive theory of stress model: Which more effectively explains people's self-reported proenvironmental behavior? Journal of Environmental Psychology, 42, 66-75. DOI: https://doi.org/10.1016/j.jenvp.2015.02.002 (in English).

10. Gupta, A., \& Singh, U. (2019). Factors Affecting Environmentally Responsive Consumption Behavior in India: An Empirical Study. Jindal Journal of Business Research, 8(1), 16-35. DOI: https://doi.org/10.1177/2278682118810274 (in English).

11. Huang, H. (2016). Media use, environmental beliefs, self-efficacy, and proenvironmental behavior. Journal of Business Research, 69(6), 2206-2212. DOI: https://doi.org/10.1016/j.jbusres.2015.12.031 (in English).

12. Lee, J. W. (2016). Energy conservation behavioral intention: attitudes, subjective norm and self-efficacy. International Conference on New Energy and 
Future Energy System, 1088/1755. DOI: https://doi.org/10.1088/1755-1315/40/1/ 012087 (in English).

13. Ojala, M. (2012). How do children cope with global climate change? Coping strategies, engagement, and well-being. Journal of Environmental Psychology, 32(3), 225-233. DOI: https://doi.org/10.1016/j.jenvp.2012.02.004 (in English).

14. Pajares, F. (1997). Current Directions in Self-Efficacy Research. In M. Maehr, \& P. R. Pintrich (Eds.). Advances in Motivation and Achievement, 10, 1-49 (in English).

15. Ramkissoon, H. R., \& Smith, L. D. G. (2014). The relationship between environmental worldviews, emotions and personal efficacy in climate change. International Journal of Arts \& Sciences, 7(1), 93 (in English).

16. Tabernero, C., \& Hernández, B. (2011). Self-efficacy and intrinsic motivation guiding environmental behavior. Environment and Behavior, 43(5), 658-675 (in English).

17. Zimmerman, B. J. (2000). Self-efficacy: An essential motive to learn. Contemporary educational psychology, 25(1), 82-91 (in English).

Received: 10.10 .2020

Accepted: 29.10.2020 